\title{
Putting faith in theory
}

\section{Seattle, Washington}

ERNEST Henley, director of the University of Washington's new $\$ 7.5$ million centre for nuclear theory, says that theoretical physicists are in short supply. Never mind that young theorists, unable to find a job in their profession, have been leaving the field in droves.

Physics needs more theorists, not fewer, Henley says. While this may seem counterintuitive (and, indeed, many physicists disagree), it is also the conclusion of a 1988 report by the Department of Energy's Nuclear Science Advisory Committee, whose chief recommendation the establishment of the centre that Henley heads - has now been implemented.

The problem, Henley says, is funding for theoretical physics, not the demand for theoreticians. And the situation is nowhere worse than in the area of nuclear physics. The Department of Energy report noted that theorists represent only 18 per cent of all nuclear physicists, as compared to 47 per cent of particle physicists. Only in optics, traditionally a relatively applied field, is the proportion of theoretical physicists lower. The panel recommended that the Department of Energy add $\$ 38$ million over five years to its budget for nuclear theory, including some $\$ 7$ million for a centre, to revive the field.

The Department of Energy, which had just committed itself to two major new nuclear physics facilities (RHIC, the Relativistic Heavy Ion Collider at Brookhaven National Laboratory and CEBAF, the Continuous Electron Beam Accelerator Facility) endorsed the plan. After a national competition, the University of Washington was selected as the site of the new theory centre. Funding was included in the 1990 budget, and the centre opened its doors in March.

Top priorities for the new centre are to spur collaborations between nuclear theorists and physicists in other fields, and to encourage graduate students and postdoctoral researchers to enter and stay in theoretical physics. The methods to be used, at least for the centre's first series of programmes this summer, appear to be basically similar to those at existing theory centres such as the National Science Foundation's Institute for Theoretical Physics at the University of California (UC), Santa Barbara. A group of between 10 and 20 scientists are invited to spend two or three months at the centre, to participate in daily hour-long seminars and informal brainstorming sessions. The object, of course, is to focus on problems that lend themselves to collaboration, and like any good dating service, the centre will be judged by the number of marriages it arranges. Several joint papers per session is an early goal.

Despite its interdisciplinary ambitions, the University of Washington centre is unique in its foundations on nuclear theory alone. Although the UC Santa Barbara centre includes nuclear theory in its charter, actual research there tends to be concentrated in condensed-matter and particle physics. The lack of research in nuclear theory has been largely due to a funding shift in the 1980s away from both nuclear physics and theory in general, says Henley. But the pendulum may be swinging back again. Many new problems in particle physics and astrophysics hinge on classic nuclear theory. Quark and gluon propagation in very dense matter, for example, turns out to be a many-body problem, raw meat for a nuclear theorist. "We're going to show the community the connections between nuclear theory and other disciplines", he says.

But a rediscovery of nuclear theory's importance will pay off only if there are good theorists to call on. Attracting young talent to the field is where the centre is most likely to make a difference. Half of the invited participants in each session are graduates or young postdoctoral researchers. And unsolicited applications from prospective theorists are likely to be viewed with favour. Five full-time staff will be young scientists on five-year appointments. That should tide them by for the first five years after their degree the years in which they are most likely to leave the field in frustration after trying and failing to get a job - and bring them to the attention of potential employers.

As massive projects such as the Superconducting Super Collider (SSC) draw an increasing number of physicists into multiyear experiments with hundreds of participants, theorists will become even more important in planning new projects, Henley predicts. "New experiments for particle physicists will come maybe once every six years. They're going to need good theorists to suggest the next experiment and to interpret the last one." With a decade to go before the SSC is up and running, the Department of Energy's new theory centre may be in the right place at the right time.

\section{SWISS SCIENCE}

\section{New president to promote ETH}

\section{Munich}

THE Swiss Federal Institute of Technology, better known by its acronym ETH (for Eidgenössische Technische Hochschule) has a new president in microbiologist Jakob Nüesch. Nüesch, 57, a graduate of the institute, returns to academic life after

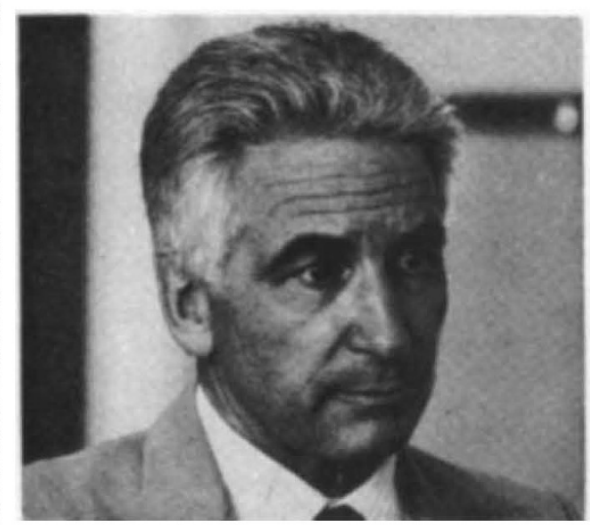

Busy man: Nüesch is looking for new professors at a rate of two a month over the next four years.

28 years in industry, most recently as director of pharmaceutical research at Ciba-Geigy in Basel.

Nüesch's appointment follows the surprise early resignation in March of mathematician Hans Bühlmann. In three years served of a scheduled five-year term, Bühlmann made several changes in the structure of ETH, introducing a department system and expanding the role of research by appointing a vice-president for research.

Emotions still run high regarding the changes brought in by Bühlmann. According to one professor, Bühlmann and his vice-president for finance, computer scientist Carl Zehnder, closed themselves off from the faculty and it seemed that "they were basically interested in seeing if they could run ETH with a computer". This professor feared that the three-year tenure of Bühlmann would leave lasting scars on ETH because of the loss of several key administrators who "cared about research". But the more sympathetic faculty members, such as biochemist Kaspar Winterhalter, say that Bühlmann and Zehnder became the undeserving scapegoats for the faculty's frustrations at bureaucratic delays and a "grotesque" shortage of space.

In addition to tackling the space problem, which he admits is urgent, Nüesch faces several daunting tasks. He will have to recruit a hundred professors in the next four years, who will shape research at ETH well into the next century. He would also like to begin to increase the number of foreign students (currently 14 per cent) and women (less than 30 per cent) at ETH. Nüesch would especially like to attract more students from European Communities member states, which he hopes will strengthen the bonds between Switzerland and the European Communities.

Steven Dickman 